\title{
The sinus tarsi approach in displaced intra-articular calcaneal fractures: a systematic review
}

\author{
Tim Schepers
}

Received: 1 December 2010 / Accepted: 20 January 2011 /Published online: 19 February 2011

(C) The Author(s) 2011. This article is published with open access at Springerlink.com

\begin{abstract}
Purpose Although open reduction and internal fixation is currently considered the gold standard in surgical treatment of displaced intra-articular calcaneal fractures, various different approaches exist including the limited lateral approach. The aim of this systematic review was to combine the results of studies using the sinus tarsi approach, which is the most frequently applied limited lateral approach.

Method A literature search in the electronic databases of the Cochrane Library and Pubmed Medline, between January 1st 2000 to December 1st 2010, was conducted to identify studies in which the sinus tarsi approach or a modified sinus tarsi approach was utilized for the treatment of displaced intraarticular calcaneal fractures. The methodological quality of the included studies was assessed using the Coleman methodology score.

Results A total of eight case series reporting on 256 patients with 271 calcaneal fractures was identified. Overall good to excellent outcome was reached in three-quarters of all patients. An average complication rate of minor wound complications of $4.1 \%$ was reported and major wound complications in $0.7 \%$. The need for a secondary subtalar arthrodesis occurred at an average rate of $4.3 \%$. The average Coleman methodology score was 56.8 (range 3972) points.

Conclusion The results, i.e. functional outcome and complication rates, of the sinus tarsi approach compare similarly or favourably to the extended lateral approach. Therefore, in the process of tailoring the best treatment
\end{abstract}

T. Schepers $(\bowtie)$

Department of Surgery-Traumatology, Erasmus MC,

University Medical Centre Rotterdam,

Room H-822k, P.O. Box 2040, 3000 CA Rotterdam,

The Netherlands

e-mail: t.schepers@erasmusmc.nl modality to the right patient and the right fracture type, the sinus tarsi approach might be a valuable asset.

\section{Introduction}

The treatment of displaced intra-articular calcaneal fractures is divided into conservative and operative management. The latter consists of open reduction internal fixation (ORIF), percutaneous reduction internal fixation (PRIF), and the primary arthrodesis (PA).

Conservative treatment, functional or using Plaster-ofParis, might be considered in fractures with little displacement or compromised soft-tissues, as well as in patients with physical contra-indications (e.g., diabetes [16], peripheral vascular disease, obesity [1, 47], smoking [1, 3, 16]) or psychological (e.g., low anticipated compliance, substance abuse [13]). Since the mid 1990s, ORIF has been considered the gold standard treatment for displaced intra-articular fractures of the calcaneus by most experts, as it generally provides good to excellent functional outcomes and the ability to anatomically restore the subtalar joint [39]. Several open surgical techniques have been described in the past, of which the extended lateral approach has been applied most frequently $[5,7,40,56]$. The main disadvantage of the open repair is the rate of wound complications, which may occur in up to $30 \%$ of patients $[2,29]$. Alternative surgical approaches to the calcaneus include the limited lateral [10, 30], obtuse-angled [26], the medial [8,9], combined lateral and medial [27, 38, 50, 51], plantar [37], Kocher approach [36], U-incision [36], and limited posterior (Gallie) approach $[17,35]$. The limited lateral approach has been described in various modifications: Palmer approach [31, 34], Smileincision [54], Ollier approach [36, 44], and the sinus tarsi approach (Fig. 1) [10, 21, 24, 45, 48]. 
Fig. 1 Example of displaced intra-articular calcaneal fracture treated via sinus tarsi approach. a Pre-operative radiograph with Böhler angle of $7.5^{\circ}$. b Skin marking of sinus tarsi incision. $\mathbf{c}$ Per-operative view with lamina spreader and provisional K-wire fixation. d Post-operative radiograph with Böhler angle of $22.5^{\circ}$
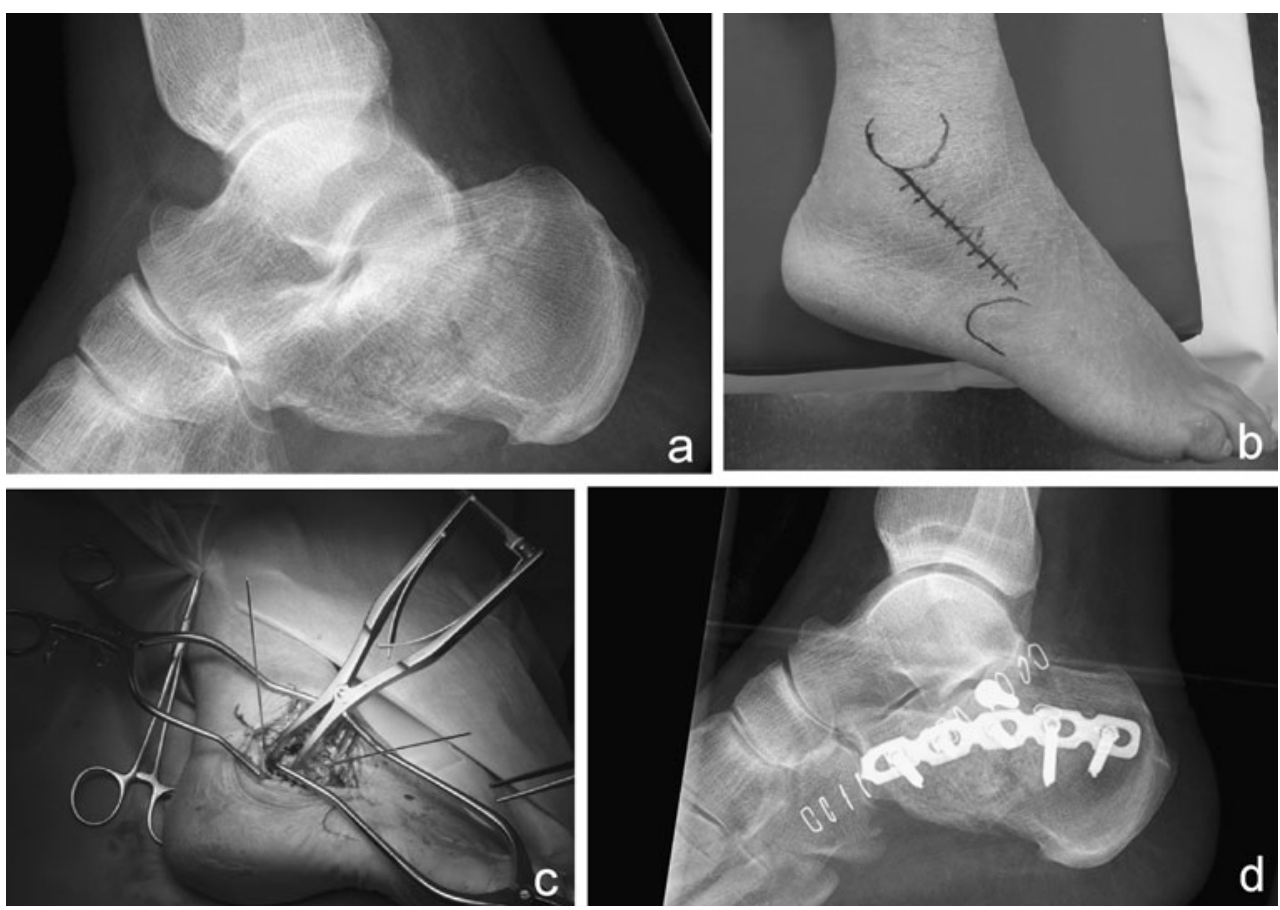

The primary aim of the current review study was to assess the functional outcome of the sinus tarsi approach, and to compare the results with the extended lateral approach, which is currently considered the gold-standard. Secondly, the complication rate was compared between both approaches.

\section{Method}

A literature search was conducted to identify studies in which the sinus tarsi approach or a modified sinus tarsi approach was utilized for the treatment of displaced intraarticular calcaneal fractures. The electronic databases of the Cochrane Library and Pubmed Medline were explored between January 1st 2000 to December 1st 2010 using the combination of the following search terms and Boolean operators: 'sinus' OR 'sinus tarsi' OR 'limited' OR 'approach' OR 'lateral' AND 'calcaneus' OR 'calcaneal' OR 'calcis'. The restriction in publication date was applied to obtain insight into current practice. Manuscript language was restricted to English, German, and Dutch literature. Publications were requested at the university medical (internet) library and reviewed. In addition, a comprehensive search of reference lists of all identified articles was conducted to find additional studies. An article was found eligible when it concerned (1) the surgical treatment of displaced intra-articular calcaneal fractures, and (2) when it used the sinus tarsi approach or a modification of this limited lateral approach.
The studies concerning the sinus tarsi approach were tested for their methodological quality according to the Coleman Methodology Score [12]. This score was described by Coleman et al. in 2000 and assesses a study on ten items for its methodological quality with a minimum of zero points (worst quality) to 100 points (best quality with low influence of bias, confounding factors and chance) [12].

\section{Results}

A total of eight case series concerning the treatment of displaced intra-articular calcaneal fractures using a sinus tarsi approach could be identified in the literature (Table 1) $[14,15,18,22,25,32,49,53]$. Two of these studies used a more extensile sinus tarsi approach $[15,18]$. Additionally, one case report was identified, which was added for completeness, but left out of further analysis [46].

\section{Literature review}

The eight case series reported on 256 patients (average 32.0 per study; range 13-99) with 271 calcaneal fractures (33.9 average per study; range 13-106). The weighted average follow-up reported in five studies was 32.9 months (range $19-52$ months).

With the exception of one study [25] all fractures were classified according to the Sanders computed-tomography classification system. The Sanders CT-classification uses the (semi-) coronal reconstruction, where the posterior subtalar 
Table 1 Overview of the literature of the last decade on the sinus tarsi approach in displaced intra-articular calcaneal fractures

\begin{tabular}{|c|c|c|c|c|c|c|c|}
\hline Study (year) & $\begin{array}{l}\mathrm{N}(\mathrm{pts}) / \\
\mathrm{N}(\# \#)\end{array}$ & $\begin{array}{l}\text { Follow-up } \\
\text { (months) }\end{array}$ & $\begin{array}{l}\text { Classification } \\
\text { (Sanders) }\end{array}$ & Outcome & $\begin{array}{l}\text { Wound } \\
\text { complication } \\
(\%)\end{array}$ & $\begin{array}{l}\text { Accurate } \\
\text { reduction }\end{array}$ & $\begin{array}{l}\text { Subtalar } \\
\text { arthrodesis }\end{array}$ \\
\hline Ebraheim et al. (2000) [14] & $99 / 106$ & 29 & $\begin{array}{l}\text { Type } 2: 71 \text { Type } 3: 25 \\
\text { Type } 4: 10\end{array}$ & $\begin{array}{r}\text { AOFAS: } 77.6 \\
75.5 \% \mathrm{G}+\mathrm{E}\end{array}$ & 8,5 & $\begin{array}{l}72 \% \text { Böhler } \\
\text { reduced }\end{array}$ & 6 secondary \\
\hline Geel and Flemister (2001) [18] & $28 / 32$ & 52 & $\begin{array}{l}\text { Type } 2: 6 \text { Type } 3: 18 \\
\text { Type } 4: 8\end{array}$ & $\begin{array}{l}\text { FOA: } 75.3 \\
59 \% \mathrm{G}+\mathrm{E}\end{array}$ & 3 & $\begin{array}{l}97 \% \text { less than } \\
2 \mathrm{~mm}\end{array}$ & 1 secondary \\
\hline Gupta et al. (2003) [22] & $28 / 32$ & N/A & $\begin{array}{l}\text { Type } 1: 2 \text { Type } 2: 20 \\
\text { Type } 3: 5\end{array}$ & N/A & 3 & $\begin{array}{l}96 \% \text { less than } \\
2 \mathrm{~mm}\end{array}$ & N/A \\
\hline Shabat and Early (2005) [46] & $1 / 1$ & N/A & Type 2: 1 & N/A & 0 & - & - \\
\hline Hospodar et al. (2008) [25] & $16 / 16$ & N/A & N/A & MFS; $75 \% \mathrm{G}+\mathrm{E}$ & 0 & $\begin{array}{l}88 \% \text { less than } \\
2 \mathrm{~mm}\end{array}$ & $\mathrm{~N} / \mathrm{A}$ \\
\hline Weber et al. (2008) [53] & $24 / 24$ & 31 & Type 2: 20 Type 3: 4 & $\begin{array}{c}\text { AOFAS; } 87.2 \\
84 \% \text { G }+ \text { E }\end{array}$ & 0 & $\begin{array}{l}100 \% \\
\text { anatomical }\end{array}$ & 0 \\
\hline Spagnolo et al. (2009) [49] & $29 / 39$ & 39 & $\begin{array}{l}\text { Type } 2: 19 \text { Type } 3: 13 \\
\text { Type } 4: 7\end{array}$ & $\begin{array}{l}\text { MFS: } 80.8 \\
74 \% \mathrm{G}+\mathrm{E}\end{array}$ & 0 & $\begin{array}{l}74 \% \\
\text { anatomical }\end{array}$ & N/A \\
\hline Femino et al. (2010) [15] & $13 / 13$ & 19 & Type 2: 9 Type $3: 4$ & N/A & 15.4 & $\begin{array}{l}100 \% \text { less } \\
\text { than } 2 \mathrm{~mm}\end{array}$ & 4 primary \\
\hline Mostafa et al. (2010) [32] & $18 / 18$ & 24 & Type 2: 12 Type 3: 6 & $\mathrm{CN}: 77.8 \% \mathrm{G}+\mathrm{E}$ & 0 & $\begin{array}{l}89 \% \text { less than } \\
2 \mathrm{~mm}\end{array}$ & N/A \\
\hline
\end{tabular}

$N(p t s) / N(\# \#)$ number of patients/number of fractures, N/A not available, AOFAS American Orthopaedic Foot Ankle Society Hindfoot score, MFS Maryland Foot Score, $C N$ Creighton-Nebraska score, FOA Functional Outcome Assessment, $G+E$ percentage of good plus excellent outcome

joint is at its widest and the sustentaculum tali is visible, and is based on the number of fracture lines with more than $2 \mathrm{~mm}$ displacement. A displaced fracture with one fracture line extending through the posterior joint is called a type-II fracture. Fractures with two fracture lines are considered type-III fractures, and type-IV fractures display three or more fracture lines. The fracture lines are lettered from lateral to medial (A, B, C). Three different forms of type II and III fractures exist, depending upon the location of fracture lines (Fig. 2). There were two Sanders type-1 (0.8\%), 157 type-2 (60.6\%), 75 type-3 (29.0\%), and 25 type-4 (9.7\%) fractures.

The functional outcome was assessed using the American Orthopaedic Foot Ankle Society hindfoot (AOFAS) score in two studies [14, 53]; these studies showed a good plus excellent result in $75.5 \%$ and $84 \%$ of cases. The Maryland Foot Score (MFS) was applied in two studies reporting a good plus excellent outcome in $75 \%$ and $74 \%[25,49]$. The Creighton-Nebraska $(\mathrm{CN})$ score was applied in one study, which reached a $77.8 \%$ good plus excellent outcome [32]. And one study used the Functional Outcome Assessment (FOA) which resulted in 59.4\% good and excellent outcome [18]. Overall good to excellent outcome was reached in three-quarters of all patients. Three studies reported on return to work $[14,18,25]$. Ebraheim et al. reported an $80 \%$ return to work, with four out of five to their pre-injury occupation [14]. In the study by Geel et al., 92\% went back to work, with most returning to the same job [18]. Hospodar et al. reported that $75 \%$ returned to work within six months [25].

Outcome correlated with the Sanders classification (type- 2 best outcome and type- 4 worse than type-3) in two studies [14, 49]. Accuracy of reduction was mentioned in all eight studies; an accurate reduction of Böhlers angle was reported in $72 \%$ by Ebraheim et al. [14]. The reduction of the posterior facet was accomplished in $74-100 \%$ of cases. Three studies reported on the need for a secondary subtalar arthrodesis, at a rate of zero [53], 3.0 [18] and $5.6 \%$ [14], with an average of $4.3 \%$. No correlation between accuracy of reduction and outcome was found by Ebraheim et al. and Geel et al. [14, 18]. However, Mostafa et al. found a correlation between improved outcome in cases with less arthrosis and better restoration of height [32].

Wound complications were reported in all studies and ranged from 0 to $15.4 \%$ (average $4.8 \%$ ). Minor wound complications encountered were two times a wound dehiscence, four cases of pin tract infection [14], and five cases of

Fig. 2 Sanders classifica tion. Line drawing of a semicoronal image of the calcaneus showing all three fracture lines $(\mathrm{A}, \mathrm{B}, \mathrm{C})$

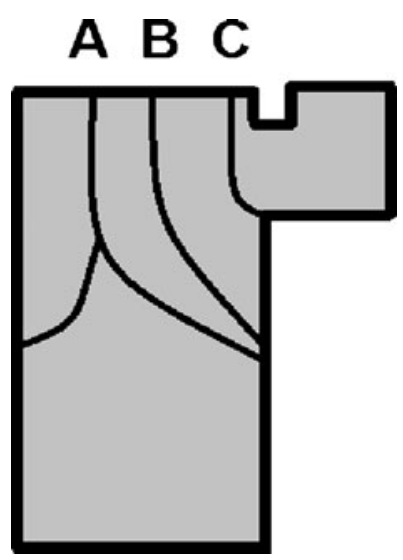


Table 2 Coleman methodological score

\begin{tabular}{|c|c|c|c|c|c|c|c|c|}
\hline Methodology criterion (min-max) & $\begin{array}{l}\text { Ebraheim } \\
\text { et al. }(2000) \\
\text { [14] }\end{array}$ & $\begin{array}{l}\text { Geel and } \\
\text { Flemister } \\
\text { (2001) [18] }\end{array}$ & $\begin{array}{l}\text { Gupta et al. } \\
(2003)[22]\end{array}$ & $\begin{array}{l}\text { Hospodar } \\
\text { et al. }(2008) \\
{[25]}\end{array}$ & $\begin{array}{l}\text { Weber et al. } \\
(2008)[53]\end{array}$ & $\begin{array}{l}\text { Spagnolo } \\
\text { et al. (2009) } \\
\text { [49] }\end{array}$ & $\begin{array}{l}\text { Femino } \\
\text { et al. }(2010) \\
{[15]}\end{array}$ & $\begin{array}{l}\text { Mostafa } \\
\text { et al. }(2010) \\
\text { [32] }\end{array}$ \\
\hline \multicolumn{9}{|l|}{ Part A } \\
\hline 1. Study size $(0-10)$ & 10 & 4 & 4 & 0 & 4 & 4 & 0 & 0 \\
\hline 2. Follow-up $(0-5)$ & 5 & 5 & 0 & 0 & 5 & 5 & 2 & 2 \\
\hline 3. Number of procedures $(0-10)$ & 10 & 10 & 7 & 10 & 7 & 10 & 0 & 7 \\
\hline 4. Type of study $(0-15)$ & 0 & 0 & 0 & 0 & 0 & 0 & 0 & 10 \\
\hline 5. Diagnostic certainty $(0-5)$ & 5 & 5 & 5 & 5 & 5 & 5 & 5 & 5 \\
\hline $\begin{array}{l}\text { 6. Description of surgical technique } \\
(0-5)\end{array}$ & 5 & 5 & 5 & 5 & 5 & 5 & 5 & 5 \\
\hline $\begin{array}{l}\text { 7. Rehabilitation and compliance } \\
(0-10) \\
\text { Part B }\end{array}$ & 10 & 10 & 10 & 10 & 10 & 10 & 10 & 10 \\
\hline 1. Outcome criteria $(0-10)$ & 7 & 4 & 0 & 5 & 7 & 7 & 2 & 4 \\
\hline 2. Outcome assessment $(0-15)$ & 5 & 12 & 0 & 0 & 0 & 0 & 0 & 0 \\
\hline 3. Selection process $(0-15)$ & 15 & 15 & 15 & 15 & 15 & 15 & 15 & 15 \\
\hline Total Coleman methodology score & 72 & 70 & 46 & 50 & 58 & 61 & 39 & 58 \\
\hline
\end{tabular}

Scores for each of the ten methods were criteria for studies reporting the results of displaced intra-articular calcaneal fractures treated via a sinus tarsi approach

superficial infection (average 4.1\%). Major wound complications were two deep infections or osteomyelitis (average $0.7 \%$ ). Concerning the latter complication, one patient with peripheral vascular disease and diabetes needed a below knee amputation [15]. Hardware removal due to complaints was reported in four studies and varied between approximately 10 and $40 \%$ [14, 18, 49, 53]. Considering nerve injuries from the approach only the sural nerve was mentioned in five studies [14, 18, 32, 49, 53]. In total, one spontaneously resolving sural neuritis was encountered [14].

Two studies reported on a comparison to the extended lateral approach, both with a historical control group. Hospodar et al. found a 75 versus $13 \%$ good to excellent result when comparing the sinus tarsi approach and the extended lateral approach using the MFS [25]. Using the AOFAS score, Weber et al. reported on a good to excellent outcome in 84 versus 66 also in favour of the sinus tarsi approach [53].

\section{Coleman methodology score}

All but one study had a retrospective design; the case series by Mostafa et al. was prospective [32]. The average Coleman methodology score (Table 2) was 56.8 (range 39-72) points.

\section{Discussion}

The present review study reports on the results of eight studies in which displaced intra-articular calcaneal fractures are treated using a sinus tarsi approach. Depending on the outcome score used, an overall good to excellent result was reached in three- quarters of cases, with an average wound complication rate of $4.8 \%$. The average secondary arthrodesis rate was $4.3 \%$.

Outcome compared favourably to the extended lateral approach in historical control groups in two studies [25, 53]. However, Hospodar et al. provided no characteristics of the extended lateral approach control group [25]. Comparison of the combined results of this study with large studies ( $n>100$ patients) of the last decade using an extended lateral approach can be broken up into four

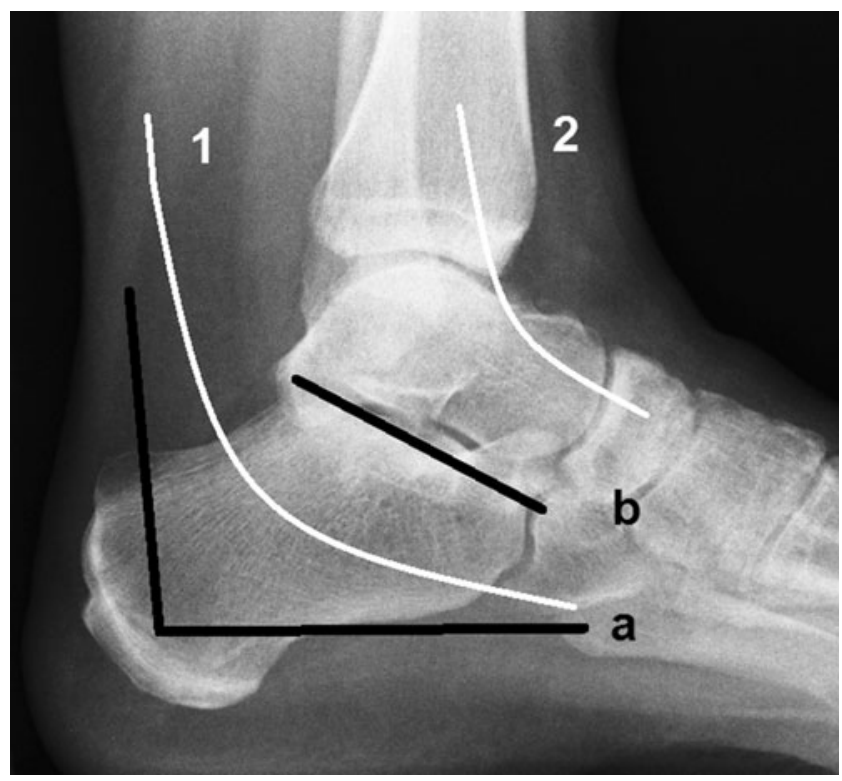

Fig. 3 Extended lateral approach versus sinus tarsi approach. Lateral radiograph with superimposed line drawings of approaches and nerves. a Extended lateral approach. b Sinus tarsi approach. 1 Sural nerve. 2 Superficial peroneal nerve 
categories: functional outcome, wound complications, the need for a secondary arthrodesis, and sural nerve injury. A good to excellent result in studies using the extended lateral approach ranged from 70 to $88 \%$ using various outcome scores $[4,33,55]$ and an AOFAS score of 83 out of 100 points in one study [28]. Considering wound complications, Weber et al. found no statistical difference in wound complications [53] between the limited and extended approaches. Concerning the literature on the extended lateral approach, superficial infections and minor wound complications occurred in $6.6-19.7 \%[7,13,23,28,55]$ and deep infections occurred in $0.5-5.6 \%[6,7,13,23,55]$. Secondary subtalar arthrodesis rates reported, in studies with adequate follow-up following an extended lateral approach, were $4.2-5.6 \%$ [7, 55]. The number of injuries to the sural nerve was low in the sinus tarsi approach. Weber et al. reported zero nerve injuries in the sinus tarsi approach and $7.7 \%$ in their patients treated via the extended lateral approach [53]. In the literature on the extended lateral approach percentages up to $10 \%$ are reported [11, 29]. This difference lies in the fact that the sural nerve is at risk both at the proximal and distal end of the extended lateral approach (Fig. 3).

The combined results of the studies with a sinus tarsi approach score similar on outcome and the need for a secondary arthrodesis, but they compare favourably on superficial and deep wound complications and sural nerve injuries.

The included studies concerning the sinus tarsi approach were tested for their methodological quality according to the Coleman methodology score [12]. The Coleman methodology score is highly reproducible between observers [52] based on the CONSORT guidelines for randomized trials [19]. The average Coleman methodology score in the present study was 56.8 points (range 39-72). This score has been previously used in surgical foot and ankle disorders [19, 20, 52], which reported average Coleman scores between 41 and 62. Studies have shown a positive correlation between publication date and Coleman score, indicating improvement in study methodology over time [12, 52]. In these studies there was also an inverse correlation between the Coleman methodology score and reported outcome, i.e. studies with lower methodology scores reported higher outcomes [12, 52]. Improvements in the quality of research can be realized, taking the items below into account.

1. Study type and characteristics. Only one study had a large enough sample size [14] and half of the studies had adequate follow-up. Most studies in this review were retrospective, with the exception of one study by Mostafa et al. [32]. Two studies used a historical control group, but only one compared baseline characteristics between both groups [53]. In order to settle the discussion whether or not the sinus tarsi approach yields comparable results to the extended lateral approach more high quality (level 1 and 2) studies are needed.

2. Outcome criteria and assessment. Most studies reported on outcome using a disease-specific functional outcome score. However, four different scores were applied. None of the studies used a generic quality of life score (e.g. Short Form-36). The AOFAS and the MFS score have been shown to have some reliability and validity [42]. Future studies will preferably show more uniformity in the use of outcome scores and include a generic quality of life score and/or a patient-based visual analogue scale on overall satisfaction with outcome [42].

3. Diagnostic certainty. All studies used pre-operative conventional radiographic imaging and computed tomo graphy. They were uniform in the use of the Sanders fracture classification, which has shown to correlate with outcome in several studies [43]. Future studies should, at least, include the Sanders classification.

Even though the sinus tarsi approach does not compare negatively to the extended lateral approach in experienced hands, the supporters of the extended lateral approach caution against its use [41]. They fear less anatomical reductions and consequently worse outcome [41]. A well designed randomized trial might settle this discussion, until that time the limited lateral sinus tarsi approach might be useful in selected cases and in patients with increased risk of complications with the use of the extended lateral approach.

In conclusion, the results of the sinus tarsi approach compare similar or favourable to the extended lateral approach, and in the process of tailoring the best treatment modality to the right patient and the right fracture type the sinus tarsi approach might be a valuable asset.

Open Access This article is distributed under the terms of the Creative Commons Attribution Noncommercial License which permits any noncommercial use, distribution, and reproduction in any medium, provided the original author(s) and source are credited.

\section{References}

1. Abidi NA, Gruen GS (1999) Operative techniques in open reduction and internal fixation of calcaneal fractures. Oper Tech Orthop 9:239-246

2. Abidi NA, Dhawan S, Gruen GS, Vogt MT, Conti SF (1998) Wound-healing risk factors after open reduction and internal fixation of calcaneal fractures. Foot Ankle Int 19:856-861

3. Assous M, Bhamra MS (2001) Should Os calcis fractures in smokers be fixed? A review of 40 patients. Injury 32:631-632 
4. Atkins RM, Allen PE, Livingstone JA (2001) Demographic features of intra-articular fractures of the calcaneum. Foot Ankle Surg 7:77-84

5. Benirschke SK, Sangeorzan BJ (1993) Extensive intraarticular fractures of the foot. Surgical management of calcaneal fractures. Clin Orthop Relat Res 292:128-134

6. Benirschke SK, Kramer PA (2004) Wound healing complications in closed and open calcaneal fractures. J Orthop Trauma 18:1-6

7. Buckley R, Tough S, McCormack R, Pate G, Leighton R, Petrie D, Galpin R (2002) Operative compared with nonoperative treatment of displaced intra-articular calcaneal fractures: a prospective, randomized, controlled multicenter trial. J Bone Joint Surg Am 84:1733-1744

8. Burdeaux BD, Jr. (1993) The medical approach for calcaneal fractures. Clin Orthop 290:96-107

9. Burdeaux BD Jr (1997) Fractures of the calcaneus: open reduction and internal fixation from the medial side a 21 -year prospective study. Foot Ankle Int 18:685-692

10. Carr JB (2005) Surgical treatment of intra-articular calcaneal fractures: a review of small incision approaches. J Orthop Trauma 19:109-117

11. Chan S, Ip FK (1995) Open reduction and internal fixation for displaced intra-articular fractures of the os calcis. Injury 26:111-115

12. Coleman BD, Khan KM, Maffulli N, Cook JL, Wark JD (2000) Studies of surgical outcome after patellar tendinopathy: clinical significance of methodological deficiencies and guidelines for future studies. Victorian Institute of Sport Tendon Study Group. Scand J Med Sci Sports 10:2-11

13. Court-Brown CM, Schmidt M, Schutte BG (2009) Factors affecting infection after calcaneal fracture fixation. Injury 40:1313-1315

14. Ebraheim NA, Elgafy H, Sabry FF, Freih M, Abou-Chakra IS (2000) Sinus tarsi approach with trans-articular fixation for displaced intra-articular fractures of the calcaneus. Foot Ankle Int 21:105-113

15. Femino JE, Vaseenon T, Levin DA, Yian EH (2010) Modification of the sinus tarsi approach for open reduction and plate fixation of intra-articular calcaneus fractures: the limits of proximal extension based upon the vascular anatomy of the lateral calcaneal artery. Iowa Orthop J 30:161-167

16. Folk JW, Starr AJ, Early JS (1999) Early wound complications of operative treatment of calcaneus fractures: analysis of 190 fractures. J Orthop Trauma 13:369-372

17. Gallie WE (1943) Subastragalar arthrodesis in fractures of the os calcis. J Bone Joint Surg 25:731-736

18. Geel CW, Flemister AS Jr (2001) Standardized treatment of intraarticular calcaneal fractures using an oblique lateral incision and no bone graft. J Trauma 50:1083-1089

19. Gougoulias N, Khanna A, Maffulli N (2010) How successful are current ankle replacements?: a systematic review of the literature. Clin Orthop Relat Res 468:199-208

20. Gougoulias N, Khanna A, Sakellariou A, Maffulli N (2010) Supination-external rotation ankle fractures: stability a key issue. Clin Orthop Relat Res 468:243-251

21. Gould N (1983) Lateral approach to sinus tarsi. Foot Ankle 3:244-246

22. Gupta A, Ghalambor N, Nihal A, Trepman E (2003) The modified Palmer lateral approach for calcaneal fractures: wound healing and postoperative computed tomographic evaluation of fracture reduction. Foot Ankle Int 24:744-753

23. Harvey EJ, Grujic L, Early JS, Benirschke SK, Sangeorzan BJ (2001) Morbidity associated with ORIF of intra-articular calcaneus fractures using a lateral approach. Foot Ankle Int 22:868-873

24. Holmes G (2005) Treatment of displaced calcaneal fractures using a small sinus tarsi approach. Foot Ankle Surg 4:35-41

25. Hospodar P, Guzman C, Johnson P, Uhl R (2008) Treatment of displaced calcaneus fractures using a minimally invasive sinus tarsi approach. Orthopedics 31:1112
26. Hussain T, Al-Mutairi H, Al-Zamel S, Al-Tunaib W (2004) Modified obtuse-angled lateral exposure of the calcaneum. Foot Ankle Surg 10:145-148

27. Johnson EE, Gebhardt JS (1993) Surgical management of calcaneal fractures using bilateral incisions and minimal internal fixation. Clin Orthop 290:117-124

28. Kienast B, Gille J, Queitsch C, Kaiser MM, Thietje R, Juergens C, Schulz AP (2009) Early weight bearing of calcaneal fractures treated by intraoperative 3D-fluoroscopy and locked-screw plate fixation. Open Orthop J 3:69-74

29. Lim EVA, Leung JPE (2001) Complications of intraarticular calcaneal fractures. Clin Orthop 391:7-16

30. Lutz M, Gabl M, Horbst W, Benedetto KP, Kunzel KH (1997) Wound margin necroses after open calcaneal reconstruction. Anatomical considerations of surgical approach. Unfallchirurg 100:792-796

31. Maxfield JE, McDermott F (1955) Experiences with the Palmer open reduction of fractures of the calcaneus. J Bone Joint Surg Am 37-A:99-106

32. Mostafa MF, El-Adl G, Hassanin EY, Abdellatif M (2010) Surgical treatment of displaced intra-articular calcaneal fracture using a single small lateral approach. Strat Traum Limb Recon 5:87-95

33. Naovaratanophas P, Thepchatri A (2001) The long term results of internal fixation of displaced intra-articular calcaneal fractures. J Med Assoc Thai 84:36-44

34. Palmer I (1948) The mechanism and treatment of fractures of the calcaneus. J Bone Joint Surg 30-A:2-8

35. Park IH, Song KW, Shin SI, Lee JY, Kim TG, Park RS (2000) Displaced intra-articular calcaneal fracture treated surgically with limited posterior incision. Foot Ankle Int 21:195-205

36. Patnaik VVG, Singla RK, Gupta PN (2001) Surgical incisionstheir anatomical basis, part III - lower limb. J Anat Soc India 50:48-58

37. Poigenfürst (1991) The dorsoplantar approach to the calcaneus. Oper Orthop Traumatol 199:254-264

38. Romash MM (1994) Open reduction and internal fixation of comminuted intra-articular fractures of the calcaneus using the combined medial and lateral approach. Oper Tech Orthop 4:157-164

39. Sanders R (2000) Displaced intra-articular fractures of the calcaneus. J Bone Joint Surg Am 82:225-250

40. Sanders R, Fortin P, DiPasquale T, Walling A (1993) Operative treatment in 120 displaced intraarticular calcaneal fractures. Results using a prognostic computed tomography scan classification. Clin Orthop 290:87-95

41. Sangeorzan BJ, Benirschke SK, Sanders R, Carr JB, Thordarson DB (2001) The literature on calcaneal fractures is highly controversial. Foot Ankle Int 22:844-845

42. Schepers T, Heetveld MJ, Mulder PG, Patka P (2008) Clinical outcome scoring of intra-articular calcaneal fractures. J Foot Ankle Surg 47:213-218

43. Schepers T, van Lieshout EM, Ginai AZ, Mulder PG, Heetveld MJ, Patka P (2009) Calcaneal fracture classification: a comparative study. J Foot Ankle Surg 48:156-162

44. Schepers T, Kieboom BCT, Bessems GHJM, Vogels LMM, Van Lieshout EMM, Patka P (2010) Subtalar versus triple arthrodesis after intra-articular calcaneal fractures. Strat Traum Limb Recon 5:97-103

45. Sclamberg EL, Davenport K (1988) Operative treatment of displaced intra-articular fractures of the calcaneus. J Trauma 28:510-516

46. Shabat S, Early JS (2005) A minimal subtalar approach to fix a calcaneal fracture and a lateral process of talus fracture in a diabetic obese patient. Orthopedics 28:1373-1374

47. Shuler FD, Conti SF, Gruen GS, Abidi NA (2001) Wound-healing risk factors after open reduction and internal fixation of calcaneal 
fractures: does correction of Bohler's angle alter outcomes? Orthop Clin North Am 32:187-192

48. Soeur R, Remy R (1975) Fractures of the calcaneus with displacement of the thalamic portion. J Bone Joint Surg Br $57: 413-421$

49. Spagnolo R, Bonalumi M, Pace F, Capitani D (2010) Calcaneus fractures, results of the sinus tarsi approach: 4 years of experience. Eur J Orthop Surg Traumatol 20:37-42

50. Stephenson JR (1987) Treatment of displaced intra-articular fractures of the calcaneus using medial and lateral approaches, internal fixation, and early motion. J Bone Joint Surg Am 69:115-130

51. Stephenson JR (1993) Surgical treatment of displaced intraarticular fractures of the calcaneus. A combined lateral and medial approach. Clin Orthop 290:68-75
52. Tallon C, Coleman BD, Khan KM, Maffulli N (2001) Outcome of surgery for chronic Achilles tendinopathy. A critical review. Am J Sports Med 29:315-320

53. Weber M, Lehmann O, Sagesser D, Krause F (2008) Limited open reduction and internal fixation of displaced intra-articular fractures of the calcaneum. J Bone Joint Surg Br 90:1608-1616

54. Wiley WB, Norberg JD, Klonk CJ, Alexander IJ (2005) "Smile" incision: an approach for open reduction and internal fixation of calcaneal fractures. Foot Ankle Int 26:590-592

55. Zwipp H, Rammelt S, Barthel S (2004) Calcaneal fractures-open reduction and internal fixation (ORIF). Injury 35(Suppl 2):SB46-54

56. Zwipp H, Tscherne H, Thermann H, Weber T (1993) Osteosynthesis of displaced intraarticular fractures of the calcaneus. Results in 123 cases. Clin Orthop 290:76-86 